\title{
THE DIAGNOSIS OF GASTRIC CANCER
}

\author{
A. P. M. Forrest, B.Sc., M.D., Ch.M., F.R,C.S.E., F.R.C.S. \\ Senior Lecturer, University Department of Surgery, Western Infirmary, Glasgow
}

Cancer of the stomach is now one of the commonest forms of malignant disease and accounts for approximately 15,000 deaths annually in England and Wales. Present-day methods of diagnosis and treatment do little to alter the natural history of the condition, and in most reported series, less than $5 \%$ of patients can hope to survive for five years. In a recent survey of 2,94I cases referred to hospital for treatment in Birmingham, the five-year survival rate was only $2.7 \%{ }^{65}$ The critical statement has been made by Livingston and Pack $^{34}$ that 'if every patient with gastric carcinoma entered the best surgical clinic in the world, $95 \%$ would still remain uncured and approximately $90 \%$ would be dead of their disease within 18 months '-figures depressingly close to those for untreated cases. ${ }^{45}$

Cancer of the stomach can be cured by surgery only if it is confined to the gastric wall and Shahon et al. ${ }^{61}$ from Minneapolis have reported a five-year survival rate of $57.1 \%$ in patients without lymphatic spread at the time of operation. Unfortunately, such favourable cases are rare and less than a third of all patients with gastric cancer referred to hospital can be treated with any hope of cure, a hope which in all but a few is without reward.

Delay in treatment does not account for these lamentable statistics-nor does the age of the patient or the site of the growth apparently influence the prognosis. As in many other forms of malignancy, the prognosis is best in those patients in whom the time between the first symptom and treatment is longest (Tables $\mathrm{I}$ and 2 ), an apparent paradox explained by the relationship of the survival of treated cases to the histological grade and thus inherent malignancy of the tumour (Table 3).

The conclusions are inescapable that, by the time most patients first experience symptoms, the growth is already incurable and that during the early stages of the development of a gastric cancer its host is entirely unaware of its presence. It is clearly the duty of every medical practitioner to ensure that this already grave situation is not made
TABLE I

Resectability Rate According to Duration of Symptoms (Walters et al. ${ }^{\div 5 \text { a }}$ )

\begin{tabular}{|c|c|c|}
\hline $\begin{array}{l}\text { Duration of } \\
\text { Symptoms }\end{array}$ & $\begin{array}{l}\text { No. of } \\
\text { Patients }\end{array}$ & $\%$ Resected \\
\hline $\begin{array}{l}<\text { I year } \\
>\text { I year }\end{array}$ & $\begin{array}{l}3,114 \\
3,128\end{array}$ & $\begin{array}{l}39.9 \\
48.9\end{array}$ \\
\hline
\end{tabular}

TABle 2

Survival Rate According to Duration of Symptoms (Swynnerton and Truelove ${ }^{66}$ )

\begin{tabular}{c|c|c|}
\hline $\begin{array}{c}\text { Duration of } \\
\text { Symptoms }\end{array}$ & $\begin{array}{c}\text { No of } \\
\text { Patients }\end{array}$ & $\begin{array}{c}\% \text { Alive at } \\
\text { 3 Years }\end{array}$ \\
\hline <6 months & 26 & 7.7 \\
6 months-2 years & 22 & 36.4 \\
$>2$ years & 24 & 54.2 \\
\hline
\end{tabular}

TABLE 3

Survival Rate According to Grade of MALIGNANCY (Broders ${ }^{5}$ )

\begin{tabular}{c|c|c}
\hline Grade & $\begin{array}{c}\text { Patients Surviving } \\
\text { Operation }\end{array}$ & $\begin{array}{c}\% \text { Alive at } \\
\text { 5 Years }\end{array}$ \\
\cline { 1 - 2 } II & 29 & 86 \\
II & 190 & 59 \\
II & 316 & 30 \\
IV & 270 & 23 \\
\hline
\end{tabular}

entirely irremediable by unnecessary delay in making a definite diagnosis.

\section{Clinical Features}

\section{Early Symptoms}

Keeping these considerations in mind it is clearly of importance to appreciate the type of symptoms initially experienced by the patient with gastric cancer, and these have been defined in several reports. ${ }^{20,32,61,66,75}$ At this stage of the disease there are no clear-cut symptoms or clinical signs and their insidious onset can be temporarily overlooked. According to Tanner, ${ }^{67}$ cancer of the stomach gives rise to symptoms only when it obstructs the peristaltic wave or causes bleeding.

In 80 to $90 \%$ of patients, the first symptom is referable to the gastro-intestinal tract and this 
usually takes the form of post-cibal pain or vague indigestion with fullness amounting to little more than a consciousness of the stomach. Mild constipation frequently occurs at this time. It is in a middle-aged patient who looks perfectly well, is well-nourished and complains only of a little epigastric discomfort, belching and newly observed constipation that cancer of the stomach must be suspected. ${ }^{2}$ Most patients have no history of previous gastric discomfort although $20 \%$ have a history of recurrent dyspepsia ${ }^{10}$ probably due to progressive atrophy of the gastric mucosa. Such patients usually notice a change in the nature of their dyspepsia which leads them to seek further medical advice.

These symptoms will be relieved by alkaline powders in $81 \%$ of cases ${ }^{75 c}$ giving both the patient and his doctor the false assurance thay they are due to a benign and unimportant gastric upset.

The second most frequent cause of symptoms is bleeding from the tumour. Frank haemorrhage from a gastric cancer is rare, but a continuous slow ooze from its surface results in the anaemia which is the mode of the onset of the disease in 8 to $22 \%$ of patients. Under these circumstances debility, breathlessness and lassitude are usually the first evidence of malignancy, symptoms apparently satisfactorily explained by the demonstration of anaemia which may be improved by taking iron.

It cannot be stressed too strongly that anaemia of this type in the middle-aged demands a thorough investigation of the gastro-intestinal tract.

In the remaining 5 to $10 \%$ of patients the initial symptoms are those of acute pyloric stenosis, perforation or severe bleeding, or arise from the presence of metastatic deposits.

\section{Late Symptoms}

By the time the patient comes to hospital his symptoms are those regarded as classical of gastric cancer, and about half the patients have pain or stenosis. ${ }^{66}$ Continuous epigastric and back pain, foul eructations, vomiting, loss of appetite, fatigue, ill-health and loss of weight are common complaints and leave little doubt as to the type and origin of the lesion.

\section{Age, Sex and Site of Tumour}

Although gastric cancer is commonest in males and in the middle-aged (average age of Mayo Clinic series of 10,890 patients-56.3 years) no age is exempt and $7 \%$ of the patients seen at the Mayo Clinic were under 40 years of age. ${ }^{75 d}$

It is generally believed that the type of symptom depends primarily on the site of the growth, those near the cardia and pylorus causing obstruction and those in the body and fundus (the silent area of the stomach) giving rise to vague dyspepsia and anaemia. It is of interest that Swynnerton and Truelove ${ }^{66}$ found that the site of the growth had little influence on the first symptom and that initially any type of dyspepsia can occur with anya site of tumour. Even in growths of the pylorus. the initial symptom was stenosis in only $10 \%$ of patients.

\section{Clinical Signs}

In a patient with early symptoms clinical signs are usually absent. By the time the patient comes to hospital loss of weight is almost invariable, and Harnett ${ }^{20}$ found that only $3.8 \%$ of $\mathrm{I}, 405$ patients. with cancer of the stomach, admitted to hospitalsw in the administrative county of London, werg not under their normal weight.

The next most common sign in hospital patient is a palpable epigastric mass, and this was noted in half of the patients studied by Harnett ${ }^{20}$ and byt Swynnerton and Truelove. ${ }^{66}$ In others, signs of pyloric stenosis with a large dilated stomach and characteristically vigorous peristalsis ${ }^{39}$ may beo present. In more advanced cases varying degrees_ of cachexia, dehydration, vitamin deficiencies and hypoproteinaemia are found.

In all patients a careful search must be made for $\stackrel{\mathbb{}}{乛}$ the presence of metastases, which in Harnetts series were discovered in $32.5 \%$ of patients. $\delta \mathrm{f}^{-}$ these the liver is the commonest site, but the supea clavicular nodes and the pelvic floor should as $0^{\circ}$ be examined. A chest radiograph may show dis-? crete nodules or miliary spread of metastatics gastric cancer. ${ }^{77}$

\section{Investigation Blood Findings}

Anaemia is a common accompaniment of cancer of the stomach, irrespective of its site, ${ }^{43}$. and was present in $45.1 \%$ of the 1,152 patients reported by Shahon and his co-workers. ${ }^{61}$ It is 3 . generally considered to be normocytic although in: a careful study of 78 patients with anaemia associated with gastric cancer, Oppenheim et al. ${ }^{43} \mathrm{O}$ found that in 25 cases it was of macrocytic normochromic or hypochromic type. The presence of음 normal maturation of red cells in the marrow, the $D$ absence of a reticulocyte response following treat-을. ment with liver and normal levels of faecaln urobilinogen differentiated it from pernicious or anaemia. The presence of anaemia is not related $N$ to the degree of hypochlorhydria ${ }^{43}$ and is probablyw accounted for by bleeding from the tumour Thrombocytopenia is a rare complication of gastrico cancer. ${ }^{37}$ In gastric cancer as in other malignant $\Phi$ conditions the erythrocyte sedimentation rate is $\stackrel{?}{?}$ commonly increased. 


\section{Faecal Occult Blood}

Overt bleeding from a gastric cancer is unusual but the presence of occult blood in the faeces is a common finding and, in most reported series of cases, occurs in about $80 \%$ of patients.

There is no reason to expect that all tumours of the stomach should bleed, and a negative faecal occult blood test does not necessarily eliminate the possibility that a cancer of the gastro-intestinal tract is present. This is particularly true in the early case.

At the same time the presence of occult blood in the faeces is an indication for further investigation and this simple test should be regarded as an essential part of the clinical examination of a patient with gastro-intestinal symptoms or anaemia.

\section{Tests of Gastric Secretion}

The association between gastric cancer and gastric juice devoid of acid (as recognized by Topfer's reagent) has been recognized since 1842 , when Golding Bird ${ }^{4}$ described a patient with a presumed gastric cancer in whom the vomitus became less acid as the disease progressed. In I879 Van den Velden ${ }^{74}$ first intubated a patient with this disease and confirmed the absence of acid in the aspirated gastric juice.

Numerous reports have since shown that from 50 to $75 \%$ of patients with gastric cancer have achlorhydria as tested by Topfer's reagent following stimulation of gastric secretion by a test meal or subcutaneous histamine. Current studies in the University of Minnesota indicate that, following a triple-histamine test in which three doses of $0.5 \mathrm{mg}$. histamine acid phosphate are given, $73 \%$ of patients with cancer of the stomach secrete no acid to Topfer's indicator compared with $36 \%$ of patients with non-neoplastic conditions. ${ }^{23}$

The degree of anaemia, loss of weight and site of growth do not appear to influence the ability of the stomach to secrete acid, ${ }^{20}$ but several reports suggest that the more advanced the lesion the higher the incidence of achlorhydria. ${ }^{14,39,48}$ This relationship would explain the Mayo Clinic findings that the resectability rate of the tumour and the survival figures are better in those patients who secrete acid than in those with achlorhydric juice. ${ }^{75 e}{ }^{751}$

Achlorhydria, as detected by Topfer's indicator, can be defined only as a $\mathrm{pH}$ change between 3 and 4 , and it was shown by Polland and Bloomfield $^{\mathbf{4 4}}$ that, in patients with such apparent achlorhydria, the administration of histamine might cause a fall in the $\mathrm{pH}$ of the gastric juice, indicating that acid was being secreted. The definition of achlorhydria suggested by Card and Sircus, ${ }^{8}$ i.e., the failure to secrete a gastric juice of $\mathrm{pH} 6$ or less following the giving of a maximal stimulus by the augmented histamine test of Kay, ${ }^{26}$ is clearly the only logical one.

The usual tests of gastric secretion are only qualitative but the augmented histamine test allows a quantitative estimation of the output of acid from the stomach. Using this test, Card and Sircus $^{8}$ found that the average acid output of patients with gastric cancer was $7.2 \mathrm{mEq}$. hour compared to 15 to $20 \mathrm{mEq}$. in normal controls. According to Card, ${ }^{7}$ patients with gastric cancer have a low acid output almost without exception, although complete absence of acid as measured by $\mathrm{pH}$ is rare. It is of interest that in his recent survey of 500 normal subjects tested by the augmented histamine tests, all had acid in their gastric juice, a finding which draws attention to the inadequacies of previous methods of gastric analysis. (Compare with $36 \%$ of ' achlorhydrics' in 906 normals reported by Niazi et al. ${ }^{42}$ )

From the clinical point of view it is clearly of the utmost importance to realize that the presence of acid in the gastric juice is not incompatible with the presence of a gastric tumour, a fact first pointed out by Mieke ${ }^{38}$ but since frequently ignored. According to Taylor ${ }^{68}$ two-thirds of patients with early cancer have acid in their stomach and normal mucosal appearances on gastroscopy. The use of gastric analysis to confirm or refute a radiological suspicion of gastric cancer is thus entirely without foundation.

The presence of sarcinae, Candida albicans, Giardia lamblia and the Boas-Oppler bacillus are common to other achlorhydric states, while starch grains and undigested meat indicate stenosis. ${ }^{56}$

\section{Radiology}

There is little doubt that, at the present time, a barium meal examination is the backbone of the diagnosis of gastric cancer, and most workers report an accuracy of 70 to $90 \%$ at the first examination. ${ }^{70}$ This can be increased further by repeating the examination in doubtful cases.

The radiological diagnosis of an established tumour offers little difficulty to a competent radiologist and the typical appearances of the three common types of lesions have been well described:- ${ }^{30}, 60,71$

I. Infiltration of a scirrhous carcinoma resulting in disturbance of the mucosal pattern, rigidity of the stomach wall and disordered motility with absent peristalsis (Fig. I). If limited in extent, it is seen as a straight aperistaltic plaque which pushes the barium back towards the lumen of the stomach. In the most advanced cases (leatherbottle stomach) the stomach may be contracted to a narrow rigid tube along which barium passes into the duodenum in a steady stream. If confined to 


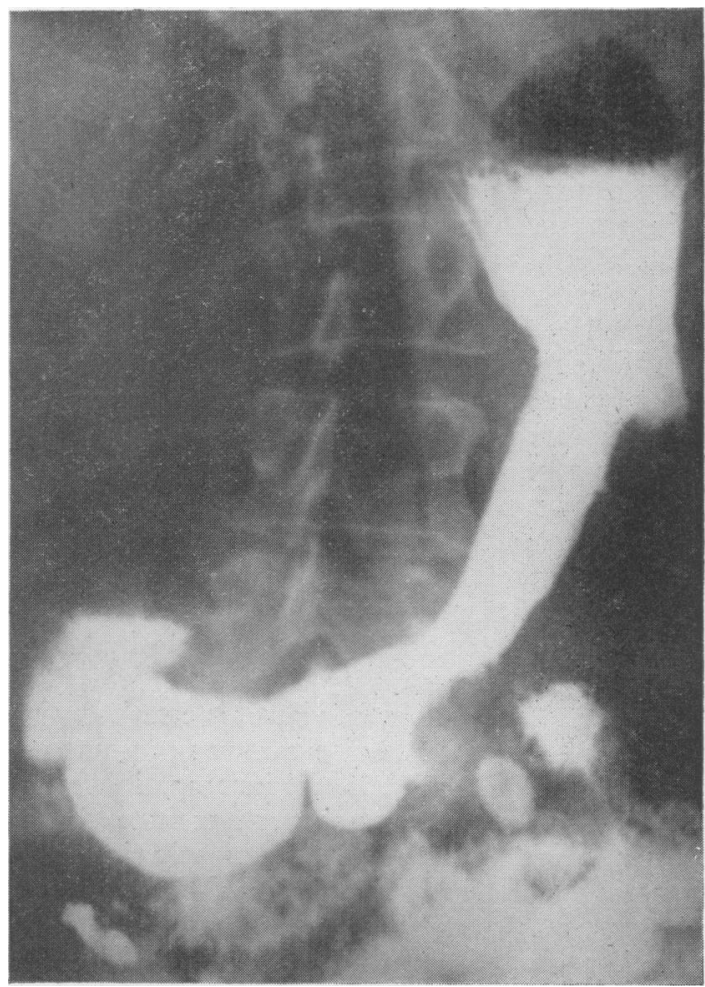

FIG. I.-Barium meal X-ray of infiltrating carcinoma of the stomach.

the pyloric region the appearances may be those of an organic pyloric stenosis and at the cardia the shape of the fundal gas bubble and the course of barium entering the stomach may be altered.

2. Filling defect of an encephaloid carcinoma (Fig. 2). The polypoid lesion forms a constant defect which has a finger-print pattern and is situated in a stomach wall showing signs of infiltration.

3. Ulceration. It is often a matter of considerable difficulty to differentiate between benign and malignant ulcers on radiological grounds alone. In its classical form the malignant ulcer sits on a plateau of cancerous tissue so that its crater appears within the confines of the gastric wall unlike the niche of a simple one which projects beyond it (Fig. 3). The irregularity of its floor, its insensitivity to palpation and the rigidity of the surrounding stomach wall may point to its true nature while its heaped-up edge may give rise to the meniscus sign of Carman ${ }^{9}$ in which the bariumfilled crater, seen in profile, forms a distinct crescentic shadow or if seen on the posterior wall is surrounded by a translucent halo. Many radiologists now consider these signs misleading and believe that the most reliable differential radio-

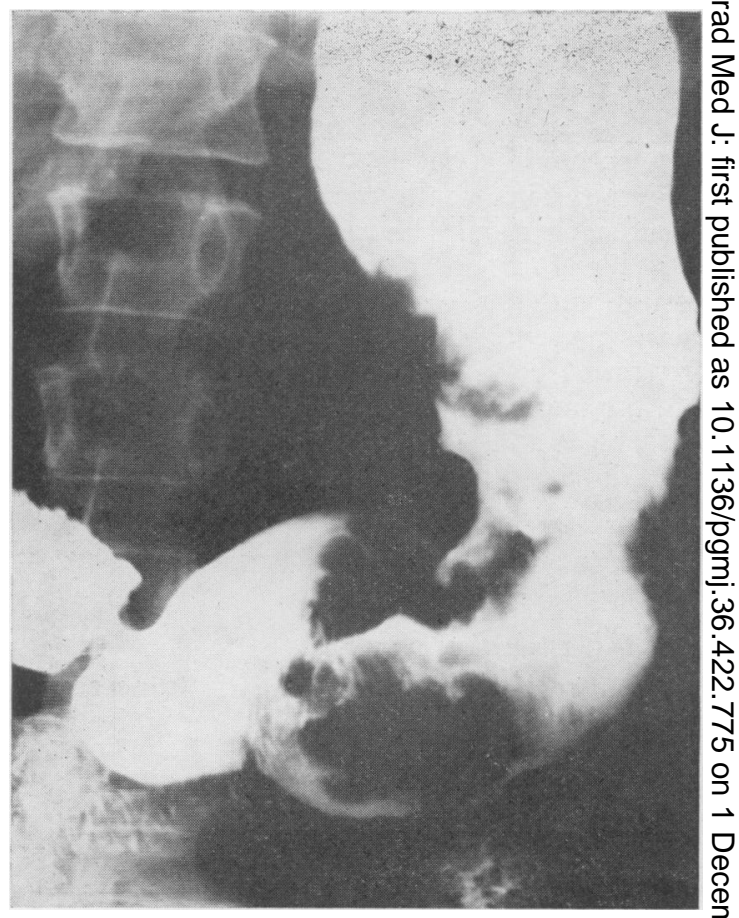

FIG. 2.-Barium meal X-ray of encephaloid carcinorna of the stomach.

logical sign is the form of the surroundian mucosal folds, which in a simple lesion converge towards the ulcer and in malignancy are sharply interrupted or distorted at its margins.

In the early stages of the disease the radiological $\frac{0}{\circ}$ signs are less prominent and a small area of dis- $\stackrel{\varrho}{\rightarrow}$ ordered mucosal pattern may be the only sign of $\overrightarrow{\vec{\partial}}$ the malignant process. ${ }^{46}$ For its detection, mucosal relief films are essential.

\section{Gastroscopy}

In approximately $2 \%$ of patients with gastric cancer, lesions missed on radiological examination 3 . may be discovered gastroscopically ${ }^{20,57}$ but it is in the interpretation of doubtful radiological findings $₹$ that this method of examination is of greatesto value. Unlike the radiologist, who sees but shadow of the lesion, the gastroscopist can view ito in its natural state, an opportunity even denied the pathologist who examines the excised specimen. N Most gastroscopists in this country prefer the $N$ flexible gastroscope designed by Hermon Taylor ${ }^{69} \mathrm{~N}$ which has a low incidence of failed examinations.

The suspicion of malignancy may be brought to the notice of the gastroscopist at the earliest stage $\frac{}{\varnothing}$ of the examination when obstruction to the passage $\stackrel{\infty}{+}$ of the instrument by a rubbery resistance which 0 cannot be overcome by steady gentle pressure may 


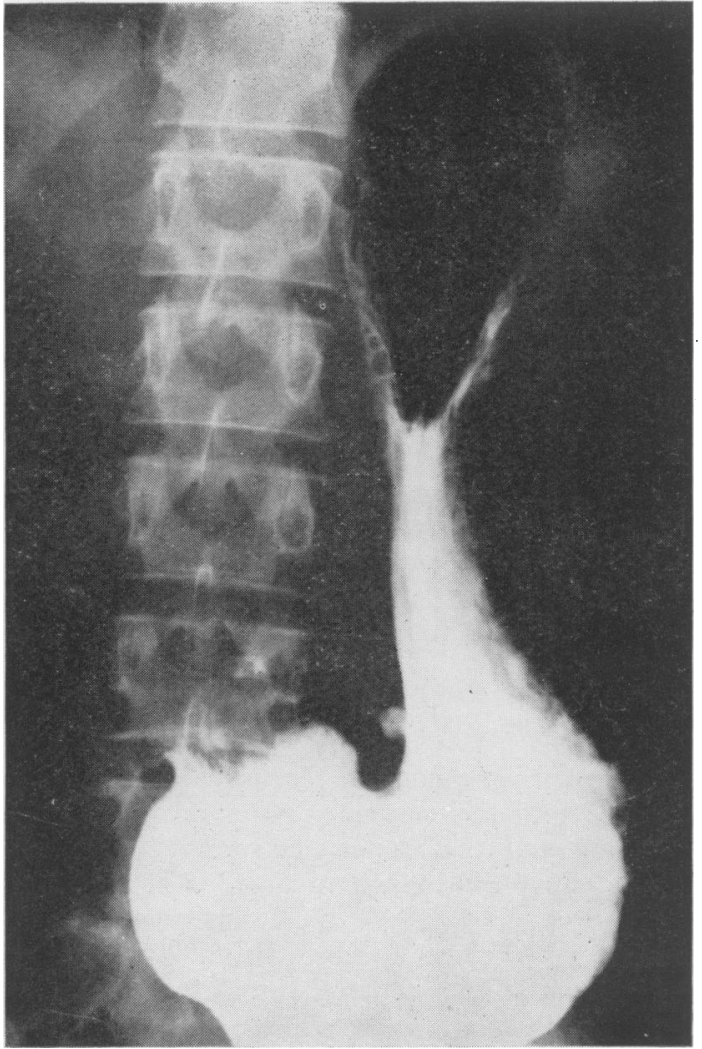

FIG. 3a.-Barium meal X-ray of simple ulcer.

indicate the presence of a tumour at the cardiac orifice. Difficulty in inflating the stomach is highly suggestive of an infiltrating lesion and the affected area has a characteristic board-like appearance with a pale, unhealthy mucosa which may contain multiple small superficial ulcers. An infiltrating lesion in the pyloric antrum is invariably accompanied by a complete lack of normal antral peristalsis. Differentiation between benign and malignant ulcers is frequently possible by gastroscopy for there is usually little difficulty in recognizing the typical simple peptic ulcer. Punched out and with clean-cut edges, it has a shiny, greyish-white slough in its base and lies in mucous membrane, which, although frequently oedematous and inflamed, is of normal colour. These typical appearances may be obscured by inflammation. Typically the malignant ulcer has a dirty brown floor and a beaded nodular edge which blends with the rigid pale and infiltrated surrounding mucosa, often studded with small superficial satellite ulcers. If the appearances are in doubt the twoview test of Taylor ${ }^{68}$ should be carried out and a repeat gastroscopy performed after three weeks' intensive medical treatment, when the subsidence

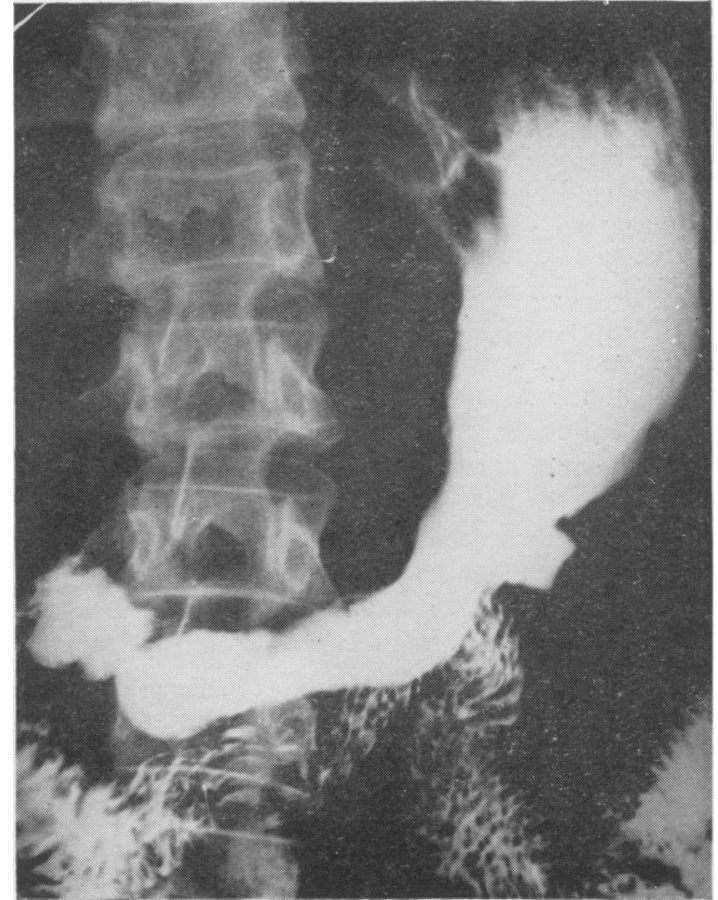

FIG. 3b.-Barium meal X-ray of malignant ulcer of the stomach.

of inflammatory reaction around a simple ulcer may allow its innocence to be clearly defined.

\section{Gastric Biopsy}

The development of a satisfactory biopsy instrument for gastric lesions by attaching a flexible biopsy forceps of standard type to a gastroscope is under study. ${ }^{3,27,28}$ A new form of biopsy instrument has also been constructed in which the cutting head guillotines a small cone of mucosa drawn into it by suction. ${ }^{13,58,72,78}$ The advantage of this instrument is that it obtains a sample of uniform thickness, but, as it is used blind, it is of value only for investigating the generalized gastric lesion. Its attachment to a gastroscope has been recently under trial. ${ }^{63}$

\section{Gastric Cytology}

It has long been recognized that the gastric juice of patients with cancer of the stomach may occasionally contain clumps of cancer cells. ${ }^{55}$ It is now known that the tendency of cancer cells to exfoliate is due to their lack of adhesiveness and Papanicolaou and his colleagues at Cornell have taken advantage of this property to develop techniques for their detection in body secretions.

Exfoliated gastric malignant cells can be differentiated from normal surface epithelial and other 
contaminating cells by their irregular shape and size, large nucleus and increased basophilia. Their loss of cytoplasmic boundaries leads to clumping and mitotic figures may be present. Schade, ${ }^{56}$ who has recently reviewed his large experience with this method of investigation in Newcastle upon Tyne, believes that the most characteristic property of a gastric malignant cell is the altered size relationship between nucleus and nucleolus.

Various methods have been developed to improve the yield of cells from the neoplastic lesion in the stomach. Many of these use some form of abrasive device, i.e. a foam-rubber sponge, ${ }^{21}$ a balloon covered with knotted silk11,51,59 and a retractable brush of boar's bristle. ${ }^{1}$ It would appear that equally satisfactory results can be obtained by the use of simple lavage methods with saline or Ringer's solution, ${ }^{18,47,56}$ and Zamcheck et $a l .{ }^{78}$ conclude that cells collected in this way have a more normal appearance. The addition of mucolytic agents such as papain ${ }^{49}$ and $x$-chymotrypsin $\operatorname{si}^{51,52}$ to the lavage fluid are considered by some to be of advantage.

There is not the slightest doubt that in expert hands gastric cytology gives a high incidence of accurate diagnosis and Schade reports that by the lavage technique he was able to diagnose correctly $\mathbf{2 5 2}$ of 282 patients with gastric carcinoma and $25 \mathrm{I}$ of 276 patients with benign conditions, results better than those reported with the use of more complex methods. ${ }^{59}$ Most workers agree that the examination is of greatest value in the early case and it is well recognized that a large ulcerating tumour may fail to exfoliate cells on account of the barrier formed by its hard necrotic base.

It is of great significance that in 29 of Schade's patients with positive cells (I9 of whom were picked up on a gastritis survey) a small surface carcinoma had not been detected by other methods of examination (radiology and gastroscopySchade $\left.{ }^{55}, 56\right)$, and similar cases have also been reported by others. ${ }^{6}, 17,31$ It may be that this method of investigation will have most application in the detection of preclinical lesions.

Evaluation. In Professor Illingworth's unit in Glasgow an attempt has been made to evaluate gastric cytology by a blind trial in which all patients reporting with suspicious symptoms were investigated in succession by radiology, gastroscopy and lavage cytology. ${ }^{6}$ In each instance the operator conducted his investigation blindly and was not informed of the findings of the other methods of investigation. The results reported by Burnett et al. (Table 4) clearly show that radiology was found to be the most accurate method of investigation. The incidence of correct diagnosis by cytology is in keeping with the results of other workers and it is only fair to point out that in this
TABLE 4

Blind Trial of Radiology, Gastroscopy and Ex- 른 foliative Cytology in the Diagnosis of Gastric CANCER (Burnett et al. ${ }^{6}$ )

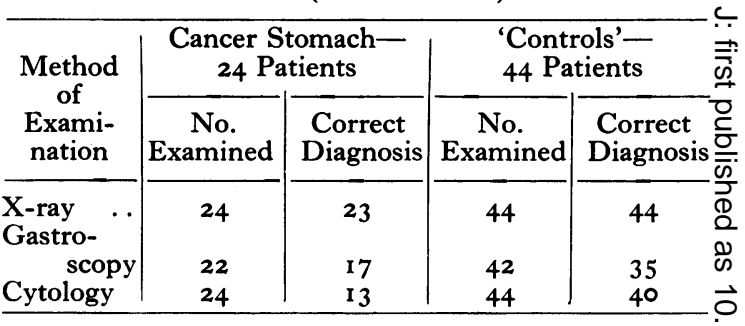

trial the cytologist was less experienced than his $\vec{\sigma}$ radiological and gastroscopic colleagues. It is noteworthy that in one patient the cytologist cor- $\frac{0}{3}$ rectly detected a small malignant lesion not visualized by either of the other methods of $\%$ investigation.

\section{Other Methods of Investigation}

Electrogastrograph. By placing an indwelling 음 electrode into the stomach, potential differences between it and a reference electrode which repre- $\square$ sent secretory muscular and nervous activity can $\varnothing$ be measured. ${ }^{15,16,24,40,54}$ Electrogastrography has 3 been shown to correctly diagnose $76 \%$ of patients with cancer of the stomach (92 of 121 cases re $\vec{P}$ ported by Sawyer et al. ${ }^{54}$; Morton ${ }^{40}$; and Goos man et al.16) by the irregularity and low potentia of the tracing. A false diagnosis of cancer was made in 24 of 153 patients with benign conditions by Sawyer et al..$^{54}$ and Goodman et al..$^{16}$

Autoradiography. On account of their high $\frac{๊}{\varnothing}$ content of DNA and RNA the cells of gastric $\varrho$ cancer take up radioactive phosphorus $\left({ }^{32} \mathrm{P}\right)$ in $\overrightarrow{\overrightarrow{\mathrm{O}}}$ greater amounts than do normal tissues and, $\exists$ following its injection, malignant gastric tissue has been shown to have a specific activity 2.8 ? times that of a normal mucous membrane. ${ }^{41}$ The insertion of a small beta particle counter to estimate specific activity is under trial.

By placing a balloon containing a photographic film into the stomach following the injection of this isotope it is possible to record the presence of a tumour by autoradiography. Using this method of investigation, Nagayama arrived at a correct $\frac{D}{O}$ diagnosis in $96 \%$ of 78 malignant lesions and $98 \%$ of 50 benign lesions of the stomach.

Uropepsin Estimations. The estimation of uropepsin as an index of gastric secretion of pepsin $\sim$ has been studied in various conditions and Gray $\omega$ et al. ${ }^{19}$ report that in 60 patients with gastric cancer the 24-hour output of uropepsin was low (mean I,8I5 \pm 29 I units compared with $3,670 \pm 159 \AA$ units in 265 normal patients). Sixty-five of 70 : patients with pernicious anaemia had zero values, 
TABLE 5

Value of X-Ray Findings in Assessing Operability OF GASTRIC CANCER (Walters et al. ${ }^{75}$ )

\begin{tabular}{c|c|c}
\hline X-ray Assessment & $\begin{array}{c}\text { No. } \\
\text { Resected }\end{array}$ & $\begin{array}{c}\% \\
\text { Resected }\end{array}$ \\
\cline { 2 - 3 } & $\mathbf{1 , 3 2 3}$ & 48 \\
Operable-2,753 patients & & \\
Operability doubttul - & & 23 \\
837 patients . & 195 & 70 \\
Inoperable-488 patients & 70 & 14 \\
\hline
\end{tabular}

the mean for the group being $17 \pm 8$ units. The scatter between patients in each group makes this estimation unreliable as a screening or diagnostic test.

Peritoneoscopy. This method of investigation is used rarely in this country and its only value in the management of patients with gastric carcinoma is to detect the presence of liver metastases.

\section{Assessment of Operability}

The only valid criteria of operability of a gastric neoplasm are to be found at laparotomy. Attempts to determine the operability of growths by radiology are misleading (Table 5) and a decision to refuse surgical exploration cannot be made on such grounds.

\section{Detection of Small Lesions}

At operation it may be difficult to detect a small malignant lesion of the stomach, particularly when the diagnosis has been made on cytological grounds. Examination of the gastric mucosa through a gastrotomy incision can be aided by using a small sigmoidoscope and a suspicious area can be biopsied and immediately examined histologically by the frozen-section technique. An alternative method is to mop the suspected spot with a swab of absorbent gelatine and make an immediate smear which can be stained and examined within a few minutes. ${ }^{36,78}$

\section{Differential Diagnosis}

The differentiation of carcinoma of the stomach from other infiltrating lesions (other tumours, Hodgkin's disease, syphilis, tuberculosis) is usually only of academic importance, and it is now considered that gastric symptoms arising in a syphilitic patient are most commonly due to ordinary lesions of the stomach.

Giant hypertrophy of the gastric mucosa may give rise to a clinical picture similar to that of cancer and the radiological appearances may be confused with those of an encephaloid cancer. The doubt can usually be resolved by gastroscopy (for recent review see Kennedy et al. ${ }^{29}$ ).

Finally, the differentiation between simple and malignant gastric ulcers may cause difficulty. In addition to the radiological and gastroscopic appearances detailed above, the site of the ulcer and its size may assist the diagnosis. In general, ulcers in the pyloric antrum and on the greater curvature of the stomach are more liable to be malignant while ulcers on the lesser curvature above the angulus are almost always simple. The larger an ulcer the more likely is it to be malignant although there is now ample evidence that even giant ulcers are frequently simple. ${ }^{25,46}$ The safety of modern anaesthesia and surgery is such that the resection of a doubtful lesion can be performed without hesitation.

\section{Conclusions}

It is quite clear that the results of treatment of cancer of the stomach can be improved only by making the diagnosis at an earlier stage of the disease before the patient has any symptoms.

Radiology is still the most applicable and reliable method of detecting an early lesion of the stomach and according to Kirklin ${ }^{30}$ all lesions large enough to be seen macroscopically can be diagnosed on the screen and film. Mass radiological surveys of normal individuals produce too low a yield of tumours to be economical (five of 8,009 patients over 40 years of age reported by St. John et al., ${ }^{64}$ Dailey and Miller,12 and Wigh and Swenson ${ }^{76}$ ). In a recent survey of normal individuals involving 5,020 fluoroscopic and 26,875 photofluorographic examinations Sherman and Snyder ${ }^{62}$ discovered gastric malignancy in seven cases. They state that if five normal individuals over the age of 55 years are examined each day one cancer of the stomach and several adenomatous polyps will be revealed in the course of one year. Selected mass surveys of the type carried out at Minneapolis ${ }^{23}$ are less costly, although for each patient diagnosed approximately 3,000 dollars are expended. ${ }^{22}$

There is now undisputed evidence that patients with achlorhydria from atrophic gastritis and pernicious anaemia have a higher incidence of gastric cancer than the general population (see Lennox ${ }^{33}$ ), and the Minneapolis figures indicate that this is approximately five times. In their special survey of $3,5^{16}$ achlorhydric patients over a $9 \frac{1}{2}$-year period, these workers discovered cancer of the stomach in 38 patients and gastric polyps in a further $3 \%$. In the same period none of their normochlorhydric patients under survey developed a gastric lesion.

Also surveyed in the Minneapolis scheme were patients who had a family history of cancer (known to increase the incidence ${ }^{35}$ ), a positive faecal occult blood test and a haemoglobin of less than I I g. \%. In these additional groups no cases of gastric cancer have so far come to light.

It may be that the initial detection of achlorhydria can be made more easily by the technique 
of tubeless gastric analysis, which has recently been simplified to a rapid bed-side test, ${ }^{58}$ and that a method of survey based on gastric exfoliative cytology would pick up positive cases at an earlier stage of development than is possible by radiology. At the present time it is clear that in all hospitals and clinics particular attention should be paid to the follow-up of patients with atrophic gastritis and pernicious anaemia in whom barium meal examinations should be performed at least once a year.

\section{REFERENCES}

I. AYRE, J. E., and OREN B. G. (1953), Cancer, 6, 1177.

2. BAYLE, G. L. (1839), ' Carcinoma and Other Malignant Lesions of the Stomach', p. 4. Philadelphia and London: W. B. Saunders Co.

3. BENEDICT, E. B. (1948), Gastroenterology, 11, 28 I.

4. BIRD, G. (1842), Lond. med. Gaz., 2, 391.

5. BRODERS, A. C. (1943), ' Carcinoma and Other Malignant Lesions of the Stomach', p. 139. Philadelphia and London: W. B. Saunders Co.

6. BURNETT, W., MACFARLANE, P. S., SCOTT PARK, S. D., and KAY, A. W. (1960), Brit. med. Y., 1, 753.

7. CARD, W. I. (1960), Personal communication.

8. CARD, W. I., and SIRCUS, W. (1958), 'Modern Trends in Gastro-enterology ', 2nd series, p. 177. London: Butterworth.

9. CARMAN, R. D. (1921), Ұ. Amer. med. Ass., 77, 990

10. COMFORT, M. W., KELSEY, M. P., and BERKSON, J. (1948), Proc. Mayo Clin., 23, 135.

I1. COOPER, W. A., and PAPANICOLAOU, G. N. (r948), Э. Amer. med. Ass., 151, 10.

12. DAILEY, M. E., and MILLER, E. R. (1945), Gastroenterology, $5, \mathrm{I}$.

13. DOIG, R. K., and WOOD, I. J. (1952), 'Modern Trends in Gastro-enterology ', ist series, p. 352. London: Butterworth.

14. EUSTERMAN, S. B., and BUĘERMANN, W. H. (1925) Y. Amer. med. Ass., 88, 295.

15. GOODMAN, F. N. (1942), Surg. Gynec. Obstet., 75, 583.

16. GOODMAN, F. N., COLCHER, H., KATZ, G. M., and DANGLER, C. L. (1955), Gastroenterology, 29, 598.

17. GRAHAM, R. M. (1954), Advanc. intern. Med., 6, 59.

18. GRAHAM, R. M., ULFELDER, H., and GREEN, T. $H$. (1946), Surg. Gynec. Obstet., 86, 257.

19. GRA , S. J., RAMSEY, C. G., REIFENSTEIN, R. W., and KRAKAUR, L. J. (1955), Gastroenterology, 29, 64 I.

20. HARNETT, W. L. (1947), Brit. F. Surg., 34, 379.

21. HENNING, N., and WITTE, S. (1952), Dtsch. med. Wschr., 77,1 .

22. HITCHCOCK, C. R. (1955), Gastroenterology, 29, 630.

23. HITCHCOCK, C. R., SULLIVAN, W. A., and WANGANSTEEN, O. H. (1955), Ibid., 29, 621.

2. INGRAM, P. W., and RICHARDS, D. L. (I953), Ibid., 25, 273.

25. JENNINGS, D., and RICHARDSON, J. E. (1954), Lancet, ii, 343 .

26. KAY, A. W. (I953), Brit. med. F., ii, 77.

27. KENNAMORE, B. (1940), Amer. F. dig. Dis., 7, 539.

28. KENNAMORE, B., SCHEFF, H., and WOMACK, N. A. (1946), A.M.A. Arch. Surg., 52, 50.

29. KENNEDY, F. D., DOCHERTY, M. B., and WAUGH, J. M. (1054), Cancer, 7,671.

30. KIRKLIN, B. R. (r943), 'Carcinoma and Other Malignant L. sions of the Stomach', p. 37. Philadelphia and London: W. B. Saunders Co.

3r. KLAYN.AN, M. I., MASSEY, B. W., PLETICKA, S., GALAMBOS. J. T., BRANDBOUUR, L., KIRSNER, J. B., and PALMER, W. L. (1955), Gastroenterology, 29, 854 .

32. LADUE, J. S., ,TURISON, P. J., MCNEER, G., and PACK, G. T. (1950), A.M.A. Arch. Surg., 60, 305 .

33. LENNOX, B. (1958), 'Cancer', vol. 2, p. I18. London: Butterworth.

34. LIVINGSTON, E. M., and PACK, G. T. (1939), 'End Results in the Treatment of Cancer, p. Ir3. New York and London: Paul B. Hoeber Inc.

35. MAKLIN, M. T. (1955), Gastroenterology, 29, 507.

36. MAROUN, T. (1957), 'Gastro-duodenal Ulcer and Cancer', vol. I, p. II 3. Beyrouth: L'Université Libanaise.

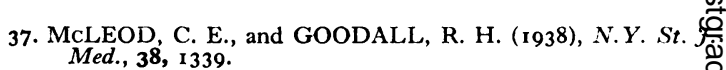

38. MIEKE, W. (1890), ' Uber die Salzsaure bei Magen carcinom?울 Wurtzburg: Diss.

39. MORLEY, J. (1937), Brit. med. F., ii, 950.

40. MORTON, H. S. (1954), Ann. roy. Coll. Surg. Engl., 15, 35 IC 41. NAGAYAMA, K. (1957), ' Gastro-duodenal Ulcer and Cancer '; vol. I, p. ro9. Beyrouth: L'Université Libanaise.

42. NIAZI, S., STATE, D., TRELOAR, A. Fi, and WANGAN STEEN, O. H. (1949), Surgery, 26, 3.

43. OPPENHEIM, A., ABELS, J. C., PACK, G. T., anf RHOADS, C. P. (1945), f. Amer. med. Ass., 127, 273.

44. POLLAND, W. S., and BLOOMFIELD, A. L. (1930), Bulf Fohns Hopk. Hosp., 46, 307.

45. POLLARD, H. M., and HENLEY, K. S. (1955), Gastro응 enterology, 29, 526 .

46. PYGOTT, F. (1958), 'Modern Trends in Gastro-enterology, (s) 2nd series, p. 130. London: Butterworth.

47. RASKIN, H. F., KIRSNER, J. B., and PALMER, W. Li(1958), Ibid., and series, p. 76. London: Butterworth.

48. ROBERTSON, J. (1935), Lancet, ?', 131 .

49. ROSENTHAL, M., and TRAUT, H. F. (1951), Cancer, 4, 4.

50. RUBIN, C. E. (1953), Proc. Inst. Med. Chicago, 19, 268.

51. RUBIN, C. E., and BENDITT, E. P. (1955), Cancer, 8, 113

52. RUBIN, C. E., MASSEY, B. W., KIRSNER, J. B., PALMEKW W. L., and STONECYPHER, D. D. (1953), Gastroenterology, 25, II9.

53. RUBIN, C. E., GOLDGRABER, M. B., and SMITH, CN (1953), Ibid., 25, 31 .

54. SAWYER, P. N., RHOADS, J. E., and PANZER, R. (1949) Surgery, 26, 420 .

55. SCHADE, R. O. K. (1958), Brit. med. F., i, 743.

56. SCHADE, R. O. K. (r960), 'Gastric Cytology'. London: Edward Arnold.

57. SCHINDLER, R. (1957), ' Gastro-duodenal Ulcer and Cancer vol. I. Beyrouth: L'Université Libanaise.

58. SEGAL, H. L., and MILLER, L. L. (1955), Gastroenterolog 29, 633 .

59. SEYBOLT, J. F., and PAPANICOLAOU, G. N. (1957), Toid 33, 369 .

60. SHANKS, S. C., and KERLEY, P. (1958) 'Textboot i $\overrightarrow{0}$ X-ray Diagnosis', 3rd edit. Edinburgh and London: E. ST Livingstone.

6r. SHAHON, D. B., HOROWITZ, S., and KELLY, Wग्गें(1056), Surgery, 39, 204.

62. SHERMAN, R. S., and SNYDER, E. (1960), f. Amer. mee Ass., 174, 949.

63. SHINER, M. (1956), Lancet, ii, 178.

64. ST. JOHN, F. B., SWENSON, P. C., and HARVEY, H. D్ (1044), Ann. Surg., 119, 225.

65. STAMMERS, F. A. R. (1950), 'Treatment of Cancer in Clinical Practice ', p. 486 . Edinburgh and London: E. \& Livingstone.

66. SWYNNERTON, B. F., and TRUELOVE, S. C. (1952) Brit. med. F., i, 287.

67. TANNER, N. C. (1958), 'Cancer', vol. 4. London: Butter? worth.

68. TAYLOR, H. (I94Ia), Lancet, i, 13 I.

69. TAYLOR, H. (194Ib), Ibid., ii, 276.

70. TAYLOR, H. (1952), 'Modern Trends in Gastro-enterology $\frac{\sigma}{3}$ Ist series, p. 445. London: Butterworth.

7x. TEMPLETON, F. F. (1944), 'X-ray Examination of the Stomach'. Chicago: University Press.

72. TOMENIUS, J. (1950), Gastroenterology, 15, 498. 73. ULFELDER, H. (1957), 'Gastro-duodenal Ulcer and Cancer $\dot{S}$
vol. I, p. I07. Beyrouth: L'Université Libanaise.

74. VAN DEN VELDEN, R. (1879), Dtsch. Arch. klin. Med? 23, 369 .

75. WALTERS, W., GRAY, H. K., and PRIESTLEY, J. T. (I943), 'Carcinoma and Other Malignant Lesions of the Stomach ', (a) p. I16, (b) p. 525, (c) p. I53, (d) p. 52 , (e) p. 531 , (f) p. 540, (g) p. 169. Philadelphia and London: W. B. S31, (f) p. 540,

76. WIGH, R., and SWENSON, P. C. (1952), Proc. 2nd Canctêt Conf., $\mathrm{r}, 84 \mathrm{r}$.

77. WILLIS, R. A. (1948), 'The Pathology of Tumours', p. 4 Q London: Butterworth.

78. WOOD, I. J., DOIG, R. K., MOTTERAM, R., and HUGHE A. (1949), Lancet, i, 18.

79. Z AMCHECK, N., GRABLE, E., JANKELSON, O. M? SMALL, M., and LONGARINI,'A. (x955), Gastroenterology 29, 588. 